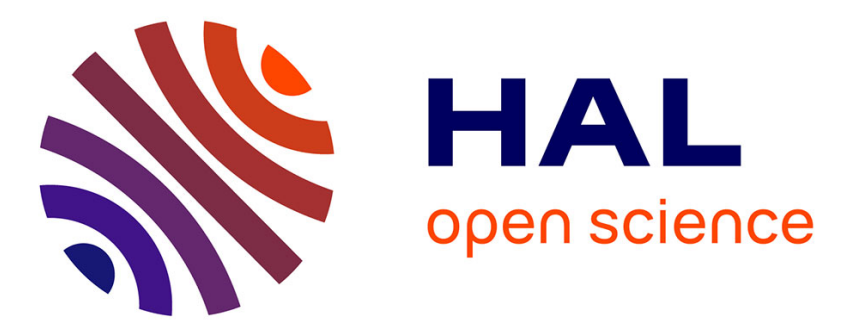

\title{
Piezoelectric response of PZT nanostructures obtained by focused ion beam
}

Denis Remiens, R.H. Liang, David Troadec, D. Deresmes, Caroline Soyer, A. Dacosta, R. Desfeux

\section{- To cite this version:}

Denis Remiens, R.H. Liang, David Troadec, D. Deresmes, Caroline Soyer, et al.. Piezoelectric response of PZT nanostructures obtained by focused ion beam. Integrated Ferroelectrics, 2008, 100, pp.16-25. $10.1080 / 10584580802540173$. hal-00800679

\section{HAL Id: hal-00800679 \\ https://hal.science/hal-00800679}

Submitted on 22 Oct 2021

HAL is a multi-disciplinary open access archive for the deposit and dissemination of scientific research documents, whether they are published or not. The documents may come from teaching and research institutions in France or abroad, or from public or private research centers.
L'archive ouverte pluridisciplinaire HAL, est destinée au dépôt et à la diffusion de documents scientifiques de niveau recherche, publiés ou non, émanant des établissements d'enseignement et de recherche français ou étrangers, des laboratoires publics ou privés.

\section{(c)(1)}

Distributed under a Creative Commons Attribution| 4.0 International License 


\title{
Piezoelectric Response of PZT Nanostructures Obtained by Focused Ion Beam
}

\author{
D. Rémiens, ${ }^{1, *}$ Liang RuiHong, ${ }^{1,2}$ D. Troadec, ${ }^{1}$ D. Deresmes, ${ }^{1}$ C. Soyer, ${ }^{1}$ \\ A. DaCosta, ${ }^{3}$ and R. Desfeux ${ }^{3}$ \\ ${ }^{1}$ (IEMN) Institut of Electronique, Microélectronique and Nanotechnoloy, UMR 8520, \\ Cité scientifique, Villeneuve d'Ascq, 59655, France \\ ${ }^{2}$ Shanghai Institute of Ceramics, Chinese Academy of Sciences (SICCAS), 1295 \\ Dingxi Road, Shanghai, 200050, P. R. China \\ ${ }^{3}$ Université d'Artois, Unité de Catalyse et de Chimie du Solide, UCCS, CNRS-UMR \\ 8181, Faculté des Sciences Jean Perrin, SP 18, 62307 Lens Cedex, France
}

\begin{abstract}
$\mathrm{Pb}\left(\mathrm{Zr}_{\mathrm{x}}, \mathrm{Ti}_{1-\mathrm{x}}\right) \mathrm{O}_{3}(\mathrm{PZT})$ microscale island $(1 \mu \mathrm{m} \sim 100 \mathrm{~nm})$ was fabricated by Focused Ion Beam (FIB) before and after its crystallization. In the first case the FIB etching is realized on amorphous films and a post annealing treatment, at the crystallization temperature of the PZT films, is necessary to cristallize the film in the perovskite phase. In the second case the etching are made on crystallized films. Local electrical properties were evaluated by piezoresponse force microscopy (PFM) technique and the degradations induce in the films are studies by Raman spectroscopy. Compared to the PZT island fabricated after crystallization, the result shows that there is noticeable enhancement in nanoscale electrical properties of PZT island fabricated before crystallization, especially when the island size decreases.
\end{abstract}

Keywords: amorphous and crystallized PZT films, PZT island, sputtering, FIB $\mathrm{Ga}^{+}$, piezoresponse force microscopy (PFM)

\section{INTRODUCTION}

Few years ago, ferroelectric films have received a worldwide technological interest for a large number of applications, in particular for Micro (or Nano)Electro-Mechanical Systems (MEMS-NEMS) [1-3]. Among the various ferroelectric films, PZT (or doped PZT) film is one of the most used materials

\footnotetext{
*Corresponding author. E-mail: denis.remiens@univ-valenciennes.fr
} 
because of its large piezoelectric coefficient. In view of the practical applications point, one of the main objective in the integration of PZT into silicon MEMS/NEMS is developing the ability to develop process compatibility (in terms of thermal budget, chemical products (nature of gaz) for etching these ferroelectric films and associated electrode materials. To this fact, several techniques have been developed [4-8]. Despite the large amount of effort in this field, there are still some problems that need to be overcome. One of the main challenges is to develop the etching process with no degradation as well on the silicon, bottom electrode and PZT material in particular in the electrical properties of the PZT film. Many papers show that the electrical performances of the films decrease after etching process. These degradations are attributed to the physical defects induced by the ion bombardment, the chemical contamination, ... The etching damage is more severe when the pattern size of PZT film is decreased to nanometer dimensions because of the 'side wall effect'. Recently, much attention has been paid to minimize the etching damage [9-12].

In this study, the submicrometer PZT island is first patterned on amorphous film by FIB method, and then make annealing process at its crystallization temperature. With these etching and annealing conditions, there is great enhancement in nanoscale electrical properties of PZT island. The results are compared with the "classical" etching process: FIB etching on perovskite PZT films.

\section{EXPERIMENTAL}

We use $\mathrm{LaNiO}_{3}$ (LNO) as a bottom electode in this work; it is well known that LNO is a favorable bottom electrode for ferroelectric film capacitor applications (in particular for fatigue). The metallic oxide LNO is a pseudo cubic perovskite with a lattice parameter of $\mathrm{a}_{\mathrm{LNO}}=3.84 \AA$; This oxide electrode can also act as a sink for oxygen vacancies and prevent their accumulation at the film/electrode interface. So, a $\mathrm{LaNiO}_{3}$ film with thickness of $250 \mathrm{~nm}$ was firstly deposited by rf magnetron sputtering on $\mathrm{SiO}_{2} / \mathrm{Si}$ substrates; its deposition was made by r.f magnetron sputtering (see Table 1). The reaction gas was argon (80\%) and oxygen $(20 \%)$. The films are produced by depositing hot i.e. the substrate is heated during the deposition, and in this case the substrates were heated to a temperature of $450^{\circ} \mathrm{C}$. The films grown have a thickness of $200 \mathrm{~nm}$. The LNO was annealed at $700^{\circ} \mathrm{C}$ in order to improve the conductivity $[13,14]$.

$\mathrm{PbZr}_{0.53} \mathrm{Ti}_{0.47}$ film with thickness of $300 \mathrm{~nm}$ was after deposited on the $\mathrm{LaNiO}_{3}$ also by rf magnetron sputtering without substrate heating and no post annealing was made. PZT films sputering conditions are given Table 2.

Then this PZT film was amorphous and it was patterned by FIB method to fabricate the PZT microscale island. FIB patterning here was performed in FEI Dual Beam STRATA 235, with a $\mathrm{Ga}^{+3}$ ion-beam, an acceleration voltage of $30 \mathrm{kV}$, a beam current of $300 \mathrm{pA}$ (corresponding to $25 \mathrm{~nm}$ spot size) and normal incident angle. Before etching, a thin 100 120 nm Pt top electrode with the 
Table 1

LNO sputtering conditions with stoichiometric target

\begin{tabular}{ll} 
Target diameter & $76.2 \mathrm{~mm}\left(3^{\prime \prime}\right)$-stoichiometric target \\
Target -Substrate distance & $60 \mathrm{~mm}$ \\
Gas & Argon + Oxygen $(20 \%)$ \\
Pressure & $10^{-2} \mathrm{mbar}$ \\
r.f Power & $2,36 \mathrm{~W} / \mathrm{cm}^{2}$ \\
Substrate & $\mathrm{Si} / \mathrm{SiO}_{2}$ \\
Substrate Temperature & $450^{\circ} \mathrm{C}$ \\
Deposition rate & $\sim 30 \AA /$ min average \\
Annealing Conditions & $1 \mathrm{~h}$ at $700^{\circ} \mathrm{C}$ in air \\
\hline
\end{tabular}

size of $1.7 \times 10^{-2} \mathrm{~mm}^{2}$ was deposited on the PZT film surface by rf sputtering to protect the top PZT island from etching damage. Then this amorphous PZT microscale island was annealed at the crystallization temperature of $625^{\circ} \mathrm{C}$ for $30 \mathrm{~min}$. For simplicity, this etching process is called amorphous etching; for comparison, microscale PZT islands with same thickness and size were also fabricated by the conventional FIB etching process, which means making the etching on the annealed crystallized PZT samples and in both cases their local electrical properties were examined. Figure 1 (a) and (b) is the flow chart of the two different etching processes and (c) is the schematic view of the FIB fabrication PZT island structure.

For the electrical properties investigation of PZT island, local piezoelectric hysteresis loops produced by a commercial Atomic Force Microscope (AFM) (Multimode, Nanoscope IIIa, Digital Instruments) were recorded. Coercive voltage $\mathrm{V}_{\mathrm{c}}$, phase switch and amplitude of relative piezoresponse signal were

Table 2

Typical PZT sputtering conditions and post annealed treatment (PZT target $=$ home made)

\begin{tabular}{ll}
\hline Target Composition & $\begin{array}{c}\text { Stochiometric target (cold pressed } \\
\text { powders/home made) }\end{array}$ \\
Target Diameter & $7.62 \mathrm{~mm}\left(3^{\prime \prime}\right)$ \\
Target-Substrate Distance & $60 \mathrm{~mm}$ \\
Pressure & $10^{-2} \mathrm{mbar}$ \\
Gas & $\mathrm{Ar}$ \\
r.f. Power & $110 \mathrm{~W}$ \\
Temperature & $\mathrm{Ambient}$ \\
Annealing Temperature & $625^{\circ} \mathrm{C}$ \\
Annealing Time & $30 \mathrm{~min}$ \\
Gas & $\mathrm{Air}$ \\
\hline
\end{tabular}




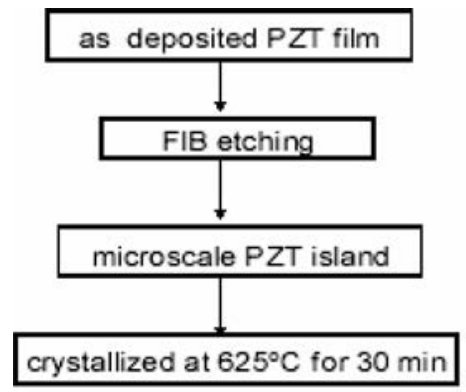

(a)

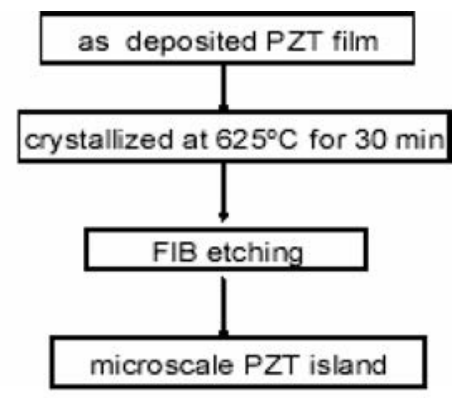

(b)

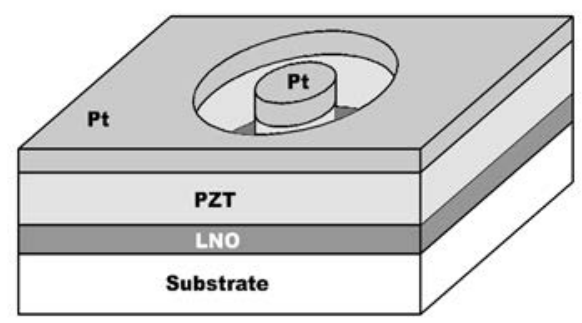

(c)

Figure 1. Flow chart of (a) amorphous FIB etching process, (b) conventional FIB etching process and (c) schematic view of FIB fabrication PZT island structure.

measured. The experiments were carried out by considering the so called "infield" mode which presents the particular characteristic, to be very close to the one used for "macroscopic" hysteresis loops recording [15-17]. In brief, PFM is based on the detection of bias-induced surface deformation; in this mode an alternative voltage $\mathrm{V}=\mathrm{V}_{\mathrm{ac}} \operatorname{Cos}(2 \pi \mathrm{ft})$ is applied between a tip brought into contact with the surface of a piezoelectric sample and grounded bottom electrode. Due to the converse piezoelectric effect, the sample oscillates with the same frequency, causing oscillations of the tip/cantilever. The signal generated by the piezoelectric vibration is extracted from the topographic signal using a lock-in amplifier. The piezoelectric response of the surface (PFM signal which form is $A \cos \varphi$ ) is detected as the first harmonic component of bias-induced tip deflection. The phase $\varphi$ of the electromechanical response of the surface yields information on the polarisation direction below the tip. For domains with polarisation vector pointing downward ( $c-$ domains), the application of a positive bias on the tip results in the expansion of the sample and the surface oscillations are in phase with tip voltage, $\varphi=0$. For domains with polarisation vector pointing upward ( $c+$ domains), $\varphi=180^{\circ}$. The piezoresponse amplitude, $P R=A / V a c$, defines the local electromechanical activity of the surface. In 
fact, both electromechanical response of the surface and electrostatic forces contribute to the PFM signal.

For our experiments, platinum/iridium coated silicon tip with a stiffness of $40 \mathrm{~N} / \mathrm{m}$ was used. The DC voltage was gradually changed from $-10 \mathrm{~V}$ to $+10 \mathrm{~V}$ within a period of 1 second. The voltage step was adjusted to $0.4 \mathrm{~V}$. The frequency of the $\mathrm{AC}$ voltage was $2 \mathrm{kHz}$ with a $1.5 \mathrm{~V}$ driving voltage.

\section{RESULTS AND DISCUSSIONS}

Typical morphology of PZT islands of $500 \mathrm{~nm}$ and $100 \mathrm{~nm}$ in diameter are shown in Fig. (2); it's correspond to Scanning Electron Microscopy (SEM) photographies of PZT nanostrutures. Fig. 3 and Fig. 4 separately show the typical local phase (a) and amplitude (b) piezoelectric hysteresis loops of 500 $\mathrm{nm}$ and $100 \mathrm{~nm}$ PZT island fabricated by different etching process (amorphous etching process and conventional process). From these figures, it can be clearly seen that the PZT island fabricated by amorphous FIB etching process has much better electrical properties compared to conventional FIB etching, especially when the island size decreases. This means the domain switching of PZT island becomes more difficult after conventional etching process. The post annealing effect after conventional etching is also investigated; with up to $625^{\circ} \mathrm{C}$ post annealing in atmosphere for 30 minutes, the amplitude increases but still lower than the sample fabricated by amorphous FIB etching process. It implies that the atmosphere post annealing can compensate for the defects induced by the conventional etching process, but can only partially recovered the electrical properties. For the island size of $500 \mathrm{~nm}$, the electrical properties degradation after conventional etching is more serious which is shown in Fig. 3. While the electrical properties of $500 \mathrm{~nm}$ PZT island fabricated by amorphous

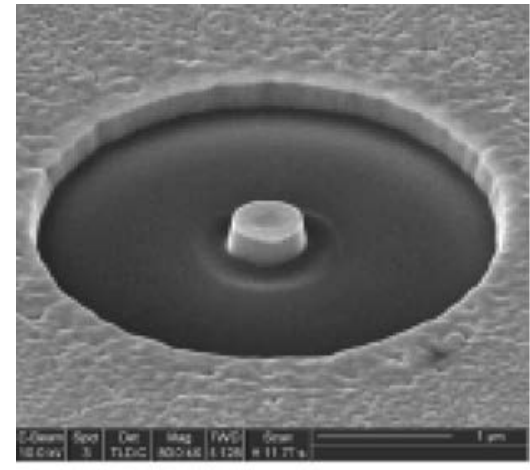

(a)

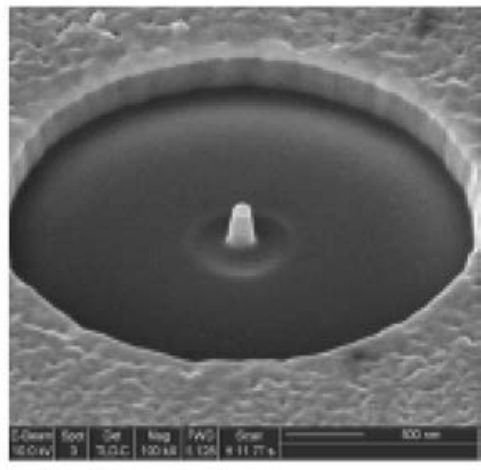

(b)

Figure 2. The morphology (SEM) of PZT island with different diameter (a)500 nm and (b) $100 \mathrm{~nm}$. 


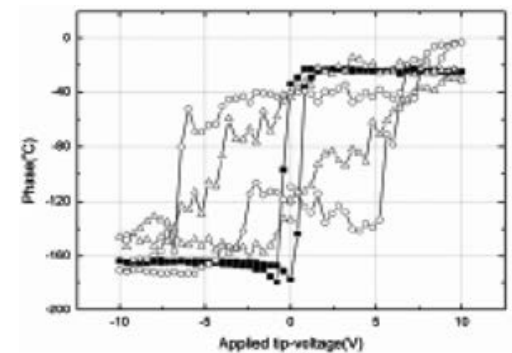

(a)

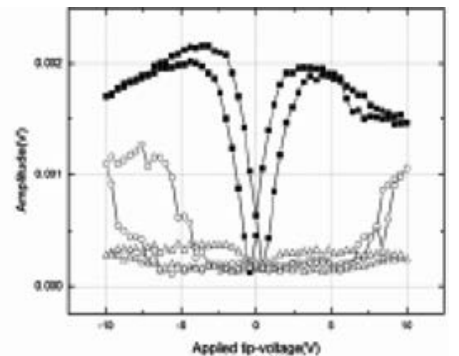

(b)

Figure 3. Typical phase (a) and amplitude (b) piezoelectric hysteresis loops of $500 \mathrm{~nm}$ PZT island fabricated by $\mathbf{a m o r p h o u s ~ F I B ~ e t c h i n g ~ p r o c e s s , ~} \mathrm{O}$ conventional etching process and $\square$ after post $625^{\circ} \mathrm{C}$ annealing.

FIB etching is almost unchanged. And there is neither domain switching nor piezoelectric amplitude in $100 \mathrm{~nm}$ PZT island fabricated by conventional etching process, even after the post annealing treatment. These notable electrical properties degradation of PZT island fabricated by conventional FIB etching maybe attributed to the side-wall effect, which is more serious when the PZT island size decreases. In Fig. 4(a), the hysteresis loop of $100 \mathrm{~nm}$ PZT island is slim and the coercive voltage is smaller compared to $1 \mu \mathrm{m}$ or $500 \mathrm{~nm}$ PZT island, which means the domain switching is easier with the decrease of PZT island size. Based on the equation 'piezoresponse (a.u.) $=A \cos \varphi$ ', the relative piezoresponse of PZT island fabricated by amorphous etching with different size is shown in Fig. 5.

Whatever the size of the island the piezoresponses of the films are maintained; it is of course very difficult to compare the island piezoresponses since it is necessary to take into account the interface between the film and the probe (presence of water,...).

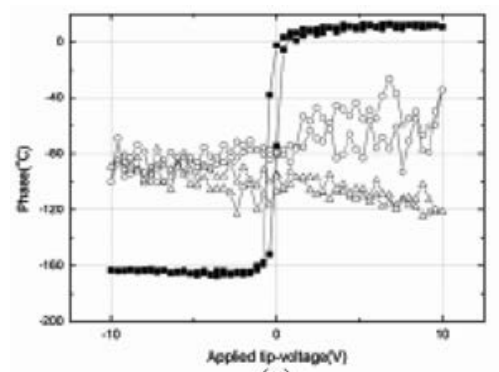

(a)

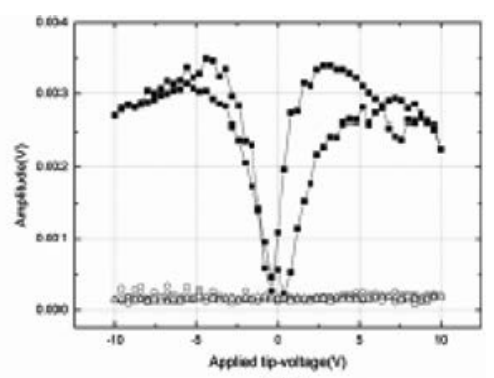

(b)

Figure 4. Typical phase (a) and amplitude (b) piezoelectric hysteresis loops of $100 \mathrm{~nm}$ PZT island fabricated by amorphous FIB etching process, o conventional etching process and $\square$ after post $625^{\circ} \mathrm{C}$ annealing. 


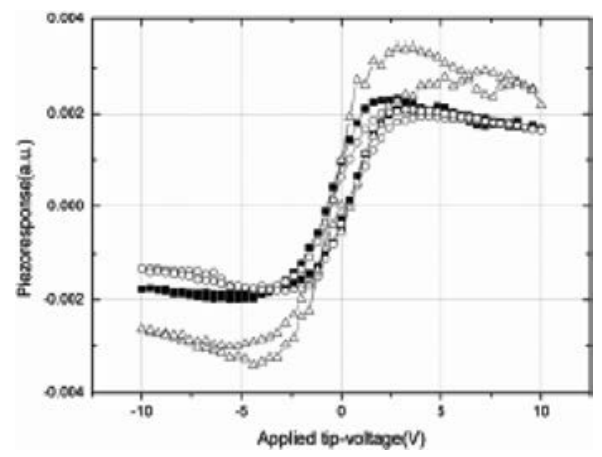

Figure 5. Relative piezoresponse of PZT island fabricated by amorphous etching with different size, $\square 1 \mathrm{um}, \Delta 500 \mathrm{~nm}$ and $\square 100 \mathrm{~nm}$.

From the above results of local electrical properties of PZT islands, it can be seen that if FIB etching is performed before PZT crystallization, the nanoscale electrical properties of PZT islands can be great improved compared to conventional etching process, especially when the island size decreases. We attribute this phenomenon to the possibility that the side wall damage can be diluted if the PZT island is fabricated by amorphous FIB etching process. Since the FIB etching is performed before PZT crystallization, there is neither grain, grain boundary nor crystalline structure, so etching rate can be almost regarded as isotropic and the roughness will be reduced. For our experiment case, the roughness of the region after amorphous FIB etching is $1.2 \mathrm{~nm}$, while the roughness of the region after conventional FIB etching is about $5 \mathrm{~nm}$. Roughness reduction can improve the electrical properties of PZT film. The second reason is that for amorphous etching process, the damaged layer on amorphous PZT film surface induced by Ga ion bombardment can be almost crystallized into the ferroelectric perovskite phase by the following anneal treatment and there is little degradation on the surface. Charge defect on the PZT surface after etching may also be reduced after following anneal treatment and this will avoid the possibility of "short-circuit" on the side wall. During the island etching, the Ga ions implantation is just on the side wall of island but after annealing, Ga ions can migrate into the crystal lattice of PZT island and there are fewer charge defect left on the side wall. The third reason is that there is no domain in the amorphous PZT film, and it is well known that the charge defects induced by the ion bombardment can limit the domain mobility and increase the coercive voltage which can be proved by the results of figure 3 and figure 4. This effect will not exist in amorphous FIB etching case.

To simulate and analyze the FIB induced damage in the PZT island sidewall layer, another FIB etching experiment was performed, shown in Fig. 6. A large square area $(7 \mathrm{um} \times 7 \mathrm{um})$ on the surface of PZT film was FIB exposed with different ion doses to simulate sidewall damage. The ion dose is controlled 


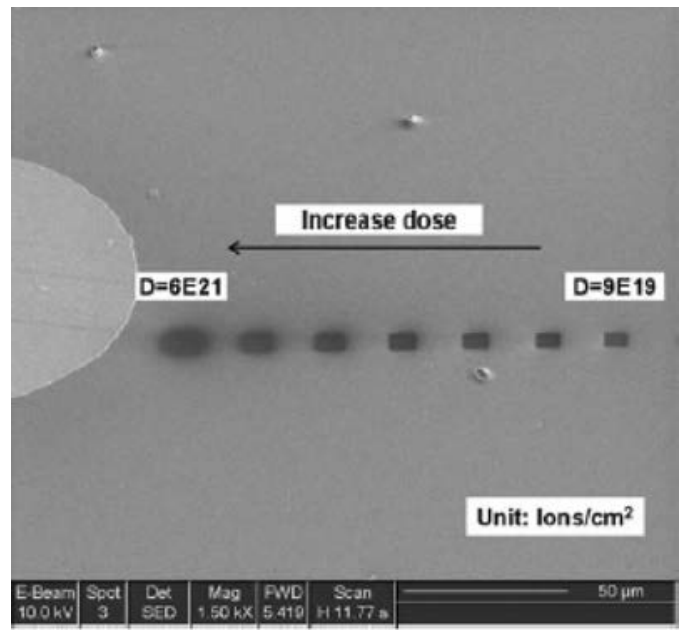

Figure 6. FIB exposed PZT layer with different Ga ion doses.

by the etching time. The lightest exposal is performed with an ion dose of about 9E19 ions/cm2 participating and the hardest is done with $6 \mathrm{E} 21$ ions $/ \mathrm{cm} 2$ participating. Raman spectra in the $200 \sim 1000 \mathrm{~cm}-1$ range were carried out with a Dilor XY-800 confocal micro-Raman spectrometer. The raman spectra were recorded using the $514.5 \mathrm{~nm}$ line of an $\mathrm{Ar} / \mathrm{Kr}$ ion laser. The incident laser beam was focused on the FIB exposed area with lum spot size and $10 \mathrm{~mW}$ power.

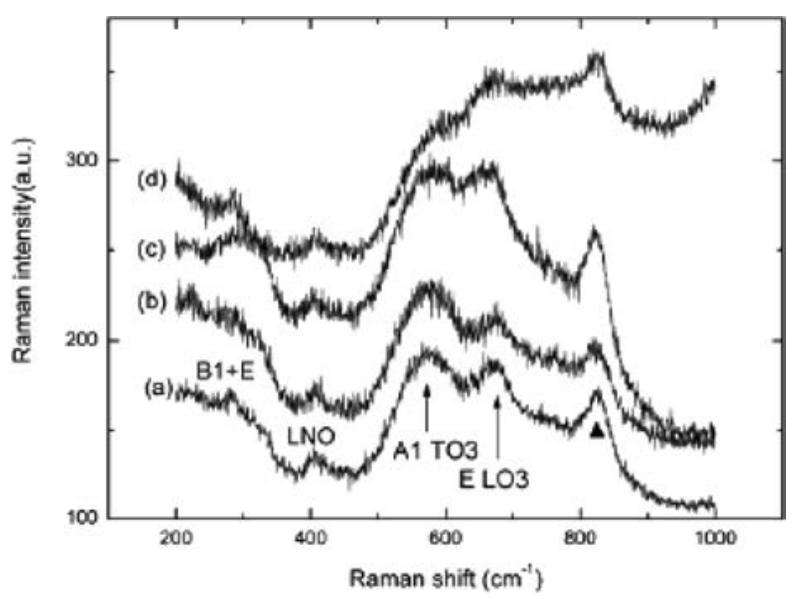

Figure 7. Raman spectra of (a) un-exposed crystallized PZT film, (b) after hardest amorphous FIB etching (6E21 ions/cm2 dose participating), (c) after lightest (9E19 ions $/ \mathrm{cm} 2)$ and (d) hardest conventional FIB etching $(6 \mathrm{E} 21$ ions $/ \mathrm{cm} 2)$. 
To confirm this suppose, a large square area (7um $\times 7 \mathrm{um})$ on the surface of PZT film was FIB exposed to simulate and analyze the FIB induced damage in the PZT island sidewall layer and the details of the experiment is mentioned above. Fig. 7 shows the Raman spectra of (a) un-exposed crystallized PZT film, (b) after hardest amorphous FIB etching (6E21 ions/cm2 dose participating), (c) after lightest (9E19 ions/cm2) and (d) hardest conventional FIB etching (6E21 ions/cm2).

In the spectra, the broadband centered at 280,572 and $676 \mathrm{~cm}-1$, can be assigned as $\mathrm{B} 1+\mathrm{E}, \mathrm{A} 1(\mathrm{TO} 3)$ and $\mathrm{E}(\mathrm{LO} 3)$, according to the modes in the single PZT crystals [17]. The band centered at $820 \mathrm{~cm}-1$ is tentatively assigned to Ti-O bond [18]. The band detected at $400 \mathrm{~cm}-1$ is attributed to LNO. After hardest amorphous etching process, the spectra profile of PZT surface is almost unchanged compared to un-etched PZT film surface. For the region after lightest conventional FIB etching, the spectrum is nearly not changed, except that the intensity of the Raman peak at $676 \mathrm{~cm}-1$ increases. While for hardest conventional etching case, Raman spectra recorded in the region exposed to the FIB shows noticeable change. The sharp increase in the intensity of the Raman band at $676 \mathrm{~cm}-1(\mathrm{E}(\mathrm{LO} 3)$ mode) maybe connected with the distortion of the tetragonal symmetry of the PZT crystalline lattice due to the ion implantation and the modification of the stress state [19-21]. The broadening of Raman scattering in 550-900 cm-1 region may be attributed to the existence of the amorphous material which is usually expected during the conventional FIB etching process. Whatever the FIB etching process is, the peak position of Raman shift does not show any change, which means that the crystalline structure still exhibits perovskite.

\section{CONCLUSION}

We can get the conclusion that there is great enhancement of the nanoscale electrical properties on PZT island fabricated by amorphous FIB etching process Roughness reduction, little degradation of the surface and no domain etching can effectively reduce the side wall effect and make this etching process a very promising etching way with no electrical properties degradation, especially when the island size decreases. The Raman spectrscopy studies confirm these results. This amorphous etching process is very beneficial to the development of the piezoelectric film applications in the field of MEMS/NEMS.

\section{ACKNOWLEDGEMENTS}

This work was supported by the post-doctoral project provided by the France ministry of research and new technology. The authors also want to thank the Université de Valenciennes et du Hainaut Cambrésis. 


\section{REFERENCES}

1. J. F. Scott and C. A. P. de Araujo, Science 246, 1400 (1989).

2. M. Moallem, M. R. Kermani, R.V. Patel, and M. Ostojic, IEEE TCST 2,757 (2004).

3. A. M. Flyn, L. S. Tavrow, S. F. Bart, R. A. Brooks, D. J. Ehrlich, K. R. Udayakumar, and L. E. Cross, J. Micrielectromech. syst. 1, 44 (1992).

4. S. Mancha, Ferroelectrics 135, 131 (1992).

5. T. Kawagughi, H. Adachi, K. Setsune, O. Yamazaki, and K. Wasa, Appl. Opt. 23, 2187 (1984).

6. K. Saito, J. H. Choi, T. Fukuda, and M. Ohue, Jpn. J. Appl. Phys., Part 2 31, L1260 (1992).

7. S. Yokoyama, Y. Ito, K. Ishihara, K. Hamada, T. Ohnishi, J. Kudo, and K. Sakiyama, Jpn. J. Appl. Phys., Part 1 34, 767 (1995).

8. C. W. Chung and C. J. Kim, Jpn. J. Appl. Phys., Part 1 36, 2747 (1997).

9. K. Torii, H. Kawakami, H. Miki, K. Kushida, T. Itiga, Y. Goto, T. Kumihashi, N. Yokoyama, M. Moniwa, K. Shoji, T. Kaga, and Y. Fujisaki, Integr. Ferroelectric 16, 21(1997).

10. M. G. Kang, K. T. Kim, and C. I. Kim, Thin solid Films 435, 222 (2003).

11. J. K. Lee, T. Y. Kim, I. Chung, and S. B. Desu, Appl. phys. Lett.75, 334 (1999).

12. Y. J. Song, N. W. Jang, S. Y. Lee, D. J. Jung, H. H. Kim, S. H. Joo, J. K. Lee, and K. Kim, Integr. Ferroelectr. 37, 47 (2001).

13. M. Detalle and D. Rémiens, J. of Crystal Growth 310, 3596-3603 (2008).

14. M. Detalle, G. Wang, D. Rémiens, P. Ruterana, P. Roussel, and B. Dkhil, J. Cryst. Growth 305, 137 (2007).

15. G. E. Menk, S. B. Desu, W. Pan, and D. P. Vijay, Mat. Res. Soc. Sym. Proc. 433, 189 (1996).

16. R. Desfeux, C. Legrand, A. Da Costa, D. Chateigner, R. Bouregba, and G. Poullain, Surf. Sci. 600219 (2006).

17. C. Legrand, A. Da Costa, R. Desfeux, C. Soyer, and D. Rémiens, Appl. Surf. Sci. 253, 4942 (2007).

18. A. Ferri, A. Da Costa, R. Desfeux, M. Detalle, G. S. Wang, and D. Rémiens, Integrated Ferroelectric 91, 80 (2007).

19. J. F. Meng, R. S. Katiyar, and G. T. Zou, Phys. Status. Solidi A 164, 851 (1997).

20. X. Lou, X. Hu, M. Zhang, F. D. Morrison, S. A. T. Redfern, and J. F. Scott, J. Appl. Phys. 99, 044101 (2006).

21. J. Frantti, V. Lantto, S. Nishio, and M. Kakihana, Phys. Rev. B 59, 12 (1999).

22. J. F. Meng, R. S. Katiyar, G. T. Zou, and X. H. Wang, Phys. Status Solidi A 164, 851 (1997).

23. K. Nomura, Y. Takeda, M. Maeda, and N. Shibata, Jpn. J. Appl. Phys. Part 1 39, 5247 (2000). 